CLINICAL REMARKS on

\section{THE PRESENT POSITION AND SCOPE OF LITIIOLAPAXY.}

ILluSTRATED BY A RECENT SERIES OF 165 CASES OF THE OPERATION FROM THE WRITER'S PRACTICE.

BY P. J. FREYER, M.A., M.D., M.CH., Surgeon-Major H. M. Bengal Army, and Civil Surgeon, Moradabad.

My pap)r entitled "Recent Experiences in Surgery of Stone in the Bladder: 100 Litholapaxies and 32 Lithotomies," 1 brought down the record of my operations for stone in the bladder-553 in number by all methods - to the middle of April, 1889. Ihuring the period that has elapsed since that time down to the end of February, 1891, ont of 168 cases of stone in the bladder which have come under my treatment, in patients of all ages from 2 years to 90 , no fewer than 165 have been dealt with by litholapaxy.

Sex and Age: Duration of Treatment.--There were amongst these 165 litholapaxy cases 99 adults - namely, 96 males and 3 females and 66 male children, or lads up to the age of 15 years. The average age of the adult males was 513 years, varying from 18 to 90 ; that of the male children $7 \frac{1}{1}$ years, varying from 2 to 15 ; and that of the three females $52 \frac{1}{3}$ years. The average number of days spent ip hospital or under treatment (in case of patients in private practice) was, in the case of adult males, 6 , varying from 2 to 28 days; in the case of male chiidren, 5. nearly, varying from 2 to 21 days; and in the case of females, 4 days. It should be mentioned, however, that in most instances the patients were kept in hospital one, two, or three days more than was absolutely necessary, merely as a precautionary measure and for purposes of observation. In no one case was the patient allowed to leave hospital till he had completely recovered.

Weight of Calculi.-The average weight of the débris of calculus removed was in adult males 242 grains, varying from 3 grains to 3 ounces and one drachm; in children 108 grains, varying from $2 \frac{1}{2}$ grains to 3 ounces and $2 \frac{1}{4}$ drachms; and in women 435 grains. The weights here given are those of the debris when thoroughly dry.

Resurrent Stone.-These 165 litholapaxies occurred in 164 different individuals, operations Nos. 388 and 449 having been performed on the same person. On May 7, 1890, I removed from him a small phosphatic calculus, weighing 4 grains; he remained perfectly well for three months, when symptoms of stone again set in, and on December 8 th, 1890, I removed a second stone of the same composition, weighing 95 grains. Amongst these 165 cases of litholapaxy there were, in addition to the case above described, six other instances of recurrent stone--two after lithotomy and four after litholapaxy. Case 314 had undergone lateral lithotomy in his childhood, and Case 361 lateral lithotomy twice, four and ten years previously respectively. Cases 336,404 , and 426 had been operated on by metwo and a-half, seven, and two and a-half years previously and in Case 41.2 litholapaxy had been performed by another surgeon one year and a-half before. All these patients had remained well and free from urinary symptoms for long periods after the first operation, so that the second calculus in each instance had no direct connection with the first.

Second Sittings. - In my previous writings I have laid great stress on the necessity of removing the whole of the stone at one sitting; 161 out of the 165 operations now under consideration were completed at a single sitting. It will, however, be found occasionally that a last fragment will sometimes evade detection. This is, undoubtedly, a weak point in the operation; but it is a weak point which sinks into insignificance when compared with the advantages with which the operation is attended. Of the four instances in which a second sitting was necessary, in three a fragment was undesignedly left behind. In all three cases the fragment revealed itself next day by the pain, stoppage of water, and other symptoms attendant on its presence in the bladder. In Cases 309 and and 337 the fragment was removed, and in each instance the patient made an uninterrupted recovery. In Case 451 the fragment was also easily removed, but tho patient died. In the fourth case the operation was designedly divided into two parts; and, as the case is a remarkable one from many points of view, I will give it in detail.

Vesical Calculus; Second Calculus probably in Ureter.--A Mahomedan lad, Case 350 , aged 15 years, was admitted to the Moradabad Civil Hospital, December 24th, 1890, with symptoms of stone of four years' duration. He was so miserably weak that he was unable to walk or even stand up. He was in constant agonising pain, the urine passing in drops continuously day and night. The foreskin was ulcerated, the result of the patient pulling at it to relieve the pain. $\mathrm{His}$ spleen was enormously hypertrophied, measuring, roughly, 1 foot long by 10 inches broad, and literally filling the abdomen. He had constantly suffered from fever for several months, was anæmic, and his face was pinched and anxious. The lad was a living skeleton, and altogether presented a miserable spectacle--the result of long suffering. A largo stone of irregular shape was felt hy the sound. The suprapubic operation suggested itself, but a cutting operation of any kind was contraindicated by the wretched health of the boy, and particularly by the enormously enlarged spleen. Ho was placed under preparatory treatment.

On December 26th, helped by my assistant-surceon (my brother, Surgeon S. F. Freyer, Medical Staff, being present), I performed litholapaxy. I found that after slitting the floor of the meatus the largest lithotrite that would pass was a No. 9, and the largest cannula a No. 12. The stone was easily caught, but was too large for the lithotrite to lock on it. By the process of chipping off portions and scraping the sides of the calculus, I eventually reduced it to such dimensions that the lithotrite locked on it. It was fortunate that the stone was irregular in shape and fairly soft, which much facilitated the crushing. Both the lithotrite and cannula were several times introduced; and, after working for one hour, I imagined that I had completely emptied the bladder of stone, having removed a mass of débris which I roughly estimated to weigh nearly 2 ounces. On careful examination, however, I found that there was a tumour, elongated in shape, in the right groin. This I found was a second stone, situated in the direction of the right ureter, in which, at its entrance to the bladder, I came to the conclusion it was lying. The outline of the stone could be seen through the abdomen, and it could be felt in position between a finger introduced into the rectum and a hand placed on the abdomen. On introducing the lithotrite I could touch the lower end of the stone, which, however, could neither be grasped nor displaced from its position. The patient was much exhausted from chloroform; so he was put to bed, my intention heing to remove the second stone by suprapubic cystotomy shruld the boy recover from the operation which he had undergone.

During the first three days after the operation the boy conto pass urine fairly freely but with considerable dribhling. He also had slight fever every evening, but, on the whole. was growing stronger daily.

On December 30 th I found the patient in intense pain, with stoppage of urine. On passing a sound I found that the stone had shifted its position and was now lying in the bladder right up against its neck. The tumour in the groin had disappeared. The dislodging of the stone from the ureter was due, no doubt, to the other stone, on which it rested, having been removed, and the accumulation of urine behind pushing it on into the bladder.

The patient was at once anæsthetised, and litholapaxy again performed (Dr. S. F. Freyer present). The same instrumentswere used as before, and a stone of nearly the same size removed. The operation lasted $1 \frac{1}{2}$ hour, and the patient was much exhausted.

The $d e b r i s$ removed at the first sitting weighed, when dry, 767 grains, and that at the second 681 grains ; total, $1448 \mathrm{grains}$, or more than $3 \frac{1}{4}$ ounces. For the first three or four davs the lad was very low, and dribbling of urine continued, but on January'11th I had the pleasure of showing him to' SurgeonGeveral W R Rice He was then sitting up in bed quite happy ; dribbling of urine had ceased, and his general Health 
had much improved. All urinary symptoms had disappeared by January $20 t h$, and on January 22 nd he was discharged in fairly good health, the spleen being much reduced in size. On January 28 th I met the lad walking about in the streets.

It is in such cases as this that Bigelow's operation stands forth in brilliant contrast with all other forms of operation for stone.

Complications. -Amongst the 165 cases of litholapaxy there were several instances in which stone in the bladder was complicated by the coexistence of enlargement of the prostate or of urethral stricture. Cystitis was also a not uncommon complication, and in some instances the urine was fotid. Yet special treatment for this latter condition was rarely necessary, the removal of the calculus-the cause of the complication-being, as a rule, followed by a spontaneous cure of the cystitis. There were many other complications, such as disease of the kidneys, dysentery, piles, prolapse of the bowel, etc.; and some of the cases were, like No. 350, already given in detail, almost moribund when they came under treatment. Yet no case was rejected, the 168 cases of operation which form the subject of this paper being the only instances of vesical calculus that came under my treatment during the period under review. There were besides several cases of impacted urethral calculus, in five of which urethrotomy had to be performed.

It will be observed that there were several very large calculi amongst this series. Cases of this kind are always attended with interest, so I will venture to give details of one.

Large Calculus. ... R. B., Case 379, a Mahomedan male, aged 75 , admitted to the Moradabad Civil Hospital, April 14th, 1890, with symptoms of stone, which had existed six years. Large stone felt by the sound. Patient extremely weak and in great pain ; passing urine every quarter of an hour, frequently mixed with blood. Prostate much enlarged. On April 15th I performed litholapaxy. I introduced my largest lithotrite, No. 17, and at once caught the stone, but found I could make no impression on it. Eventually, one end of the stone, which was oval in shape, was caught, and with a great effort a portion was broken off. This was reduced to fine débris, and removed. I again attacked the stone, and broke off a second piece, which was treated similarly to the previous portion. This process was repeated arain and again, till the whole of the stone was disposed of. There was some bleeding during the operation, partly from the incised meatus and partly from the enlarged prostate, but the patient bore the operation well. The debris was that of an oxalate of lime calculus, and weighed $3 \frac{1}{8}$ ounces.

In the evening I found the patient wonderfully well, passing urine freely, slightly coloured with blood. There was no fever and only slight pain in the perineum, which was relieved by hot fomentations. Next day he was passing clear urine. On April 20 th he was walking about, free from all urinary symptoms, and was discharged on April 24th, in excellent health.

Prostatic Enlargement.-In cases in which the presence of stone is complicated by enlargement of the prostate I frequently find that there is considerable bleeding, the result of the passage of the instruments. Great care is necessary in such cases to see that all the fragments are removed, for they frequently get entangled in clots of blood in the bladder, which are sometimes with difficulty removed by the aspirator. Several washings are advisable after all fragments seem to have been removed.

Ancesthetics.-As a rule the patient is, of course, anæsthetised during the performance of litholapaxy. Latterly however I have, in suitable, cases, performed the operation without the use of any anæsthetic.

Female Cases.-There were, as already mentioned, three females in this series. One of them was seven months gone in pregnancy at the time of operation. This case shows that litholapaxy may be successfully undertaken in the last months of pregnancy without fear of causing miscarriage. The chief, in fact I may say the only, difficulty I have ever experienced in performing litholapaxy in the female, arises from the difficulty of retaining water in the bladder both during the crushing of the stone and the aspiration of the fragments. This difficulty I have now quite surmounted by getting an assistant to place the fore and middle fingers in the vagina and press the lower lip of the urethra against the lithotrite or cannula, as the case may be-a manœuvre which prevents the water flowing out beside the instrument.

Deaths.-There were, as I have already stated, three deaths amongst this series of 168 operations for stone in the bladder.

Peritonitis. - A., Case 307, a Mahomedan male, aged 25, admitted April 21st, 1889, with stone in the bladder, of ten or twelve years' standing. He was extremely emaciated, scarcely able to stand up, suffering from constant pain in the bladder, and had to pass his urine in drops every ten or fifteen minutes. Fæces were passed involuntarily, and he had prolapsus ani. On April 24th, I performed litholapaxy. There was considerable difficulty experienced in passing a No. 14 lithotrite through the membranous portion of the urethra. The stone was easily grasped and crushed, and the main portion of it removed through a No. 16 cannula. Great difficulty was experienced, however, in catching the last fragments, owing to the sacculated condition of the bladder. The lithotrite and cannula had to be introduced several times before they were all disposed of. The calculus was composed of oxalate of lime covered by phosphates, and the débris weighed 355 grains. The operation lasted 45 minutes. For the first two days the patient did fairly well, passing urine freely, but suffering from slight fever in the evening. On April $27 \mathrm{th}$, however, symptoms of peritonitis set in, and on April 28th these were fully developed, there being general swelling and tenderness of the abdomen, rapid breathing, temperature $103^{\circ} \mathrm{F}$., pulse 110 . Still he continued to pass clear urine, but in smaller quantities. In spite of treatment the peritonitis became more and more pronounced, and the patient died May 9 th. No necropsy was allowed.

Old Age; Exhaustion. - H., a Hindu male, Case 318, aged 90 years, admitted May' 30 th, 1889 , with the usual symptoms of stone, which had existed four years. He was little more than skin and bone, was in great agony, and had to pass urine "lhundreds of time in the day and night." He was suffering from fever, and so weak that he could not leave his bed. I placed him under preparatory treatment, but he was so clamorous to have something done to relieve his agonies, that on June 3rd I performed litholapaxy. The urethra was capacious, admitting a No. 15 lithotrite and a No. 16 cannula easily. The stone (uric acid) was large and hard, the débris weighing 2 ounces and 40 grains. The instruments were four times introduced, and the operation lasted 45 minutes. There was no bleeding. The patient was much exhausted after the operation, but rallied towards the evening, passing water freely, and without pain. On the morning of the 4 th he was very weak, the pulse being scarcely perceptible at the wrist, and he died from exhaustion at 2 P.M. that day.

Senility; two Sittings; Pneumonia.-B., a Hindu male, Case 451, aged 65, admitted December 12th, 1890, with symptoms of stone of one year and a half standing, a withered old creature, scarcely able to stand up, and in great agony. His urine was largely mixed with blood and pus, and had a fœtid stench. On passing a full-sized sound, its advance was obstructed by a tumour, which, on examination by the rectum, turned out to be an enlarged prostate. By gentle manipulation the sound was passed over the enlarged middle lobe of the prostate, and a stone felt lying behind it in the bladder. I performed the litholapaxy at once (Surgeon J. F. Tuohy being present). The stone (uric acid) was hard, the débris weighing more than $1 \frac{1}{4}$ ounce. Lithotrite No. 15 and cannula No. 16 were easily introduced several times during the operation; but the bladder was sacculated and ridged, so that much difficulty was experienced in catching some of the fragments. The operation lasted forty minutes. In the evening the patient passed urine freely and without pain; but next morning urine was passed with pain and difficulty. Suspecting that there might be a fragment left behind, I passed a sound, and detected one behind the prostate. Chloroform was at once given, the lithotrite introduced, and the fragment crushed, and removed by the aspirator.

After this the patient passed urine freely during December 13 th, but on the evening of that day high fever set in with rigors. Next morning he was found to have pneumonia of the right lung, and he was extremely weak. On December 15 th he had great dyspnœa, with almost complete suppression of urine, and, continuing to lose ground, he died on the morn- 
Table showing particulars of 165 Litholapaxy Operations.

The cases which ended fatally are printed in italics (Nos. $307,318,451$ ).

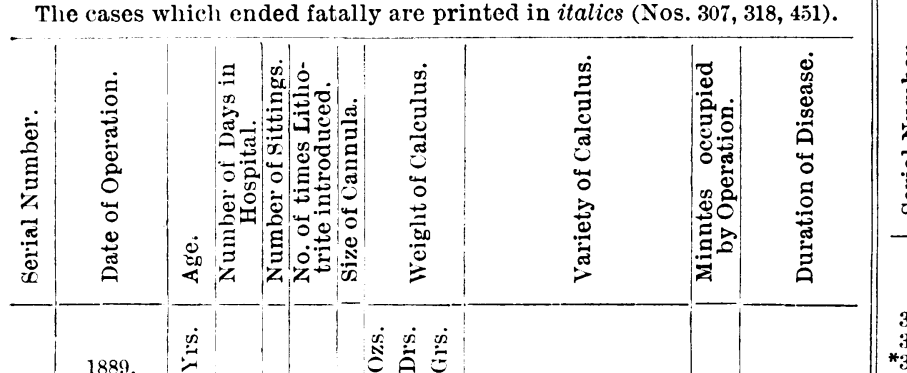

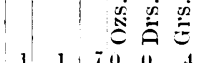

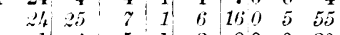

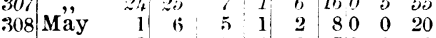
$\begin{array}{lllllllllll}309 & -1 & 2 & 6 & 5 & 2 & 3 & 70 & 0 & 42\end{array}$

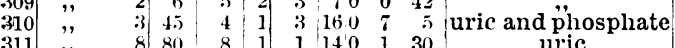
312 "

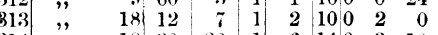
$\begin{array}{llllllllllll}314 & = & 18 & 30 & 28 & 1 & 6 & 14 & 0 & 3 & 10\end{array}$

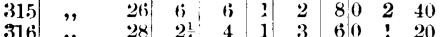

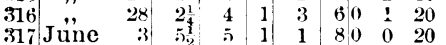

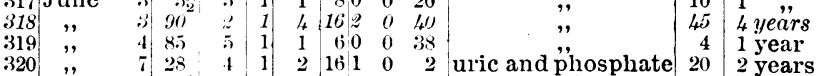

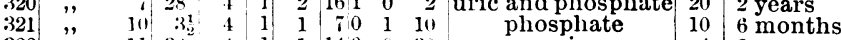

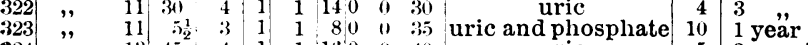

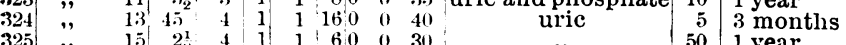

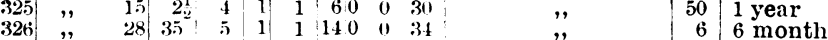

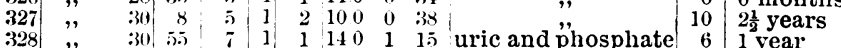

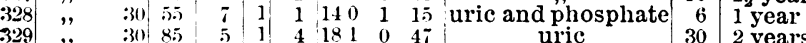

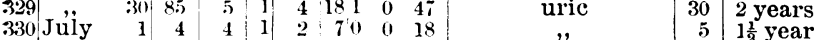

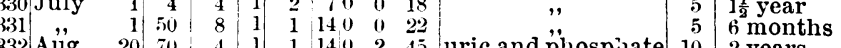

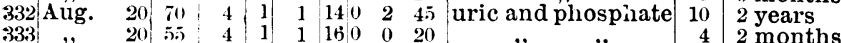

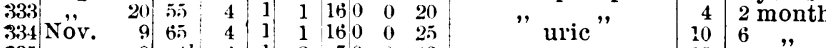

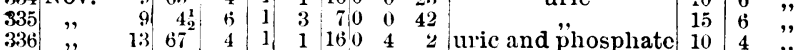

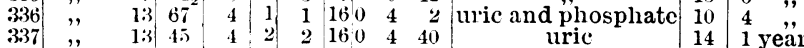

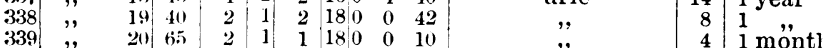

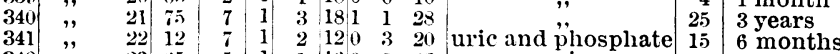

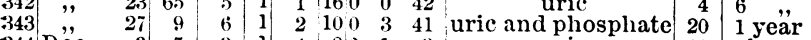

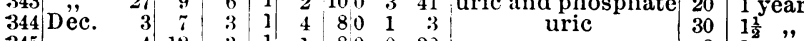

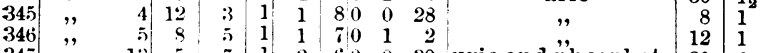

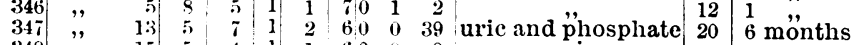

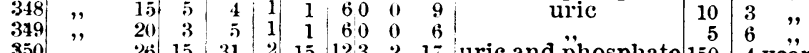

\begin{tabular}{l|llllllllllll}
350 & $\|$ & 26 & 15 & 31 & 2 & 15 & 12 & 3 & 2 & 17 & uric and phosphate 150 & 4 years
\end{tabular} \begin{tabular}{ccc|c|c|c|cc|c|c|c|c|}
\hline 1890 & 29 & 34 & 2 & 1 & 4 & 16.0 & 1 & 5 & uric & 15 & 1 year
\end{tabular} \begin{tabular}{lll|l|l|l|l|llll}
352 & Jan. & 1 & 55 & 7 & 1 & 0 & 16 & 0 & 0 & 5
\end{tabular}

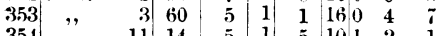

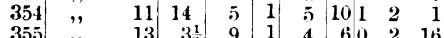

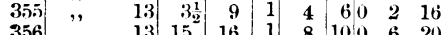

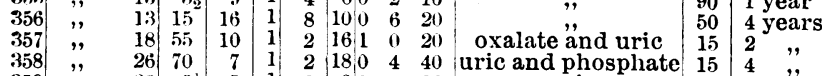

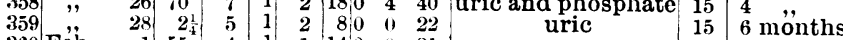

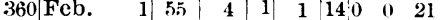

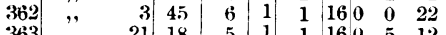

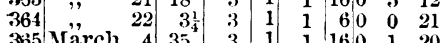

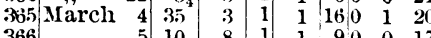
\begin{tabular}{rlll|l|l|l|l|lll}
366 & $\#$ & & 5 & 10 & 8 & 1 & 1 & 90 & 0 & 17 \\
367 &, & 8 & 14 & 5 & 1 & 1 & 100 & 1 & 20
\end{tabular}

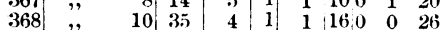
\begin{tabular}{lll|l|l|l|llll}
369 & $\#$ & 11 & 34 & 4 & 1 & 2 & 160 & 0 & 26 \\
\hline
\end{tabular} $\begin{array}{llllllllllll}369 & " & 11 & 34 & 8 & 1 & 2 & 16 & 0 & 1 & 50 \\ 370 & " & & 11 & 65 & 8 & 1 & 1 & 160 & 2 & 50\end{array}$

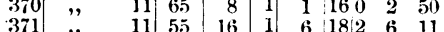

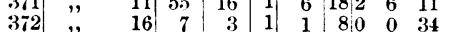

\begin{tabular}{lll|llllllllll|l}
373 & $"$ & 19 & 60 & 4 & 1 & 2 & 18 & 1 & 3 & 0 \\
3 & & &
\end{tabular}

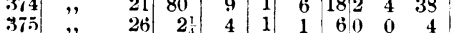

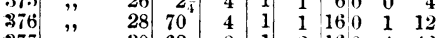
\begin{tabular}{lllllllllll}
877 & 0 & 30 & 62 & 8 & 1 & 2 & 16 & 0 & 4 & 42 \\
\hline
\end{tabular} \begin{tabular}{lll|l|l|l|l|lll|l}
379 & $\Lambda p r i 1$ & 9 & 40 & 5 & 1 & 1 & 16 & 0 & 0 & 22 \\
\hline & 15 & 75 & 9 & 1 & 7 & 18 & 3 & 1 & 0 \\
\hline
\end{tabular}

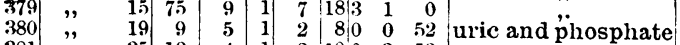

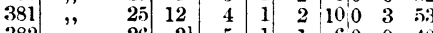

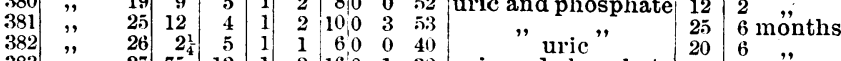

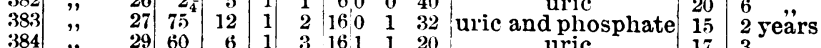

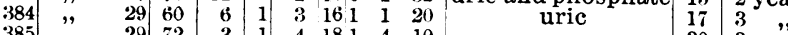

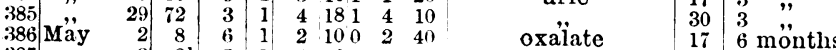
387 , $\begin{array}{lllllllll}2 & 15 & 5 & 1 & 2 & 10 & 1 & 1\end{array}$

phosp̈hate phosphate uric

oxalate
phosphate uric

,

$\ddot{\prime \prime}$

$"$

$"$

\begin{tabular}{r|ll}
8 & 3 \\
12 & 2 & years
\end{tabular} 5 months 10 2 years $\begin{array}{rl}8 & 6 \text { months } \\ 10 & 6 \text {, } \\ 15 & 2 \text { years }\end{array}$ \begin{tabular}{r|l}
8 & 3 month \\
9 & 1 year
\end{tabular} 10110 \begin{tabular}{l|l|l}
4 & 4 & years \\
7 & 6 & months
\end{tabular} 20 1 year 10 months 5
6 12 years 6 4 months 6

15.2 months

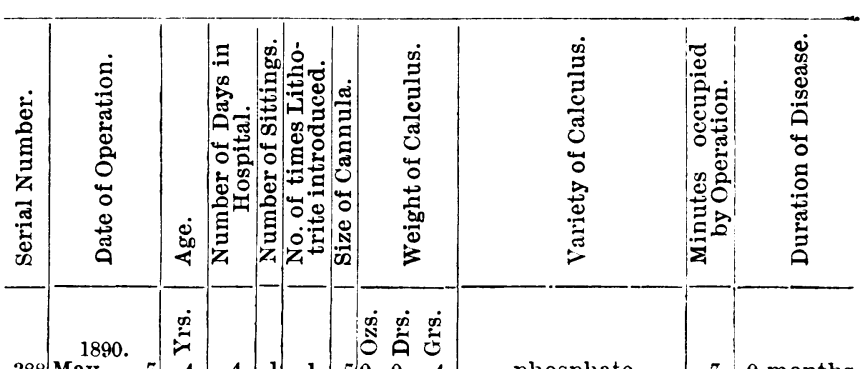

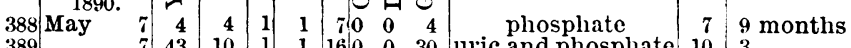

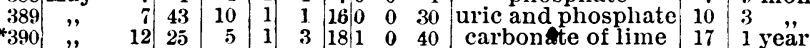

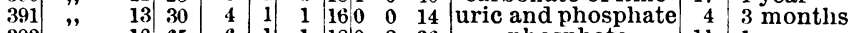

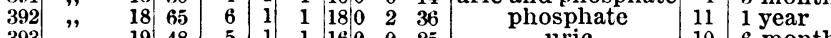

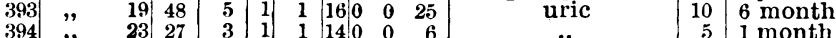
$\begin{array}{llllllllllllll}395 & \# & 26 & 11 & 4 & 1 & 1 & 10 & 0 & 2 & 25 \\ & & & & \end{array}$

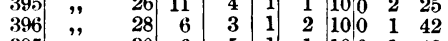
\begin{tabular}{llllllllllllll}
397 & $\# 0$ & 6 & 5 & 1 & 1 & 10 & 0 & 1 & 48 \\
\hline
\end{tabular}

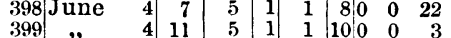

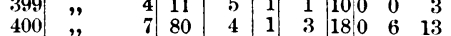

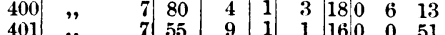

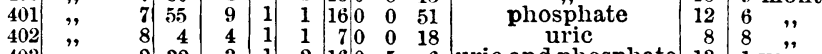

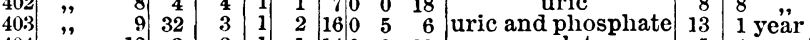
\begin{tabular}{lll|l|l|l|l|lll|l|l|l|l|l}
404 & $=$ & 18 & 3 & 2 & 1 & 1 & 14 & 0 & 0 & 11 & oxalate & 5 & 4 months
\end{tabular}

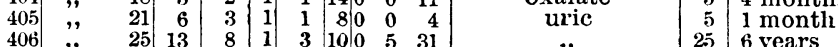

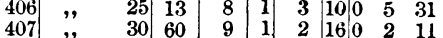

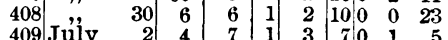

409 July

\begin{tabular}{l|ll|l|l|l|l|l|lll|}
410 &, & 4 & 40 & 6 & 1 & 2 & 14 & 0 & 0 & 26 \\
411 &, & 4 & 60 & 6 & 1 & 1 & 16 & 0 & 1 & 55 \\
\hline
\end{tabular}

$\begin{array}{lll}30 & 0 & 1 \\ 10 & \text { year } \\ \text { months }\end{array}$

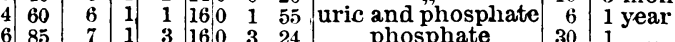

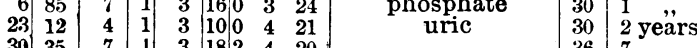

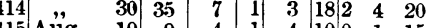

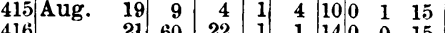

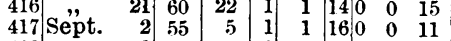

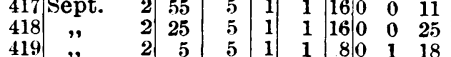

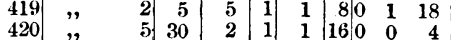

\begin{tabular}{lllllllll|lll}
421 & $\#$ & 6 & 80 & 9 & 1 & 1 & 18 & 2 & 4 & 19 \\
\hline
\end{tabular}

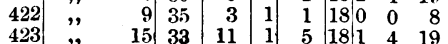

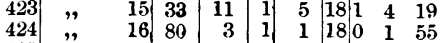

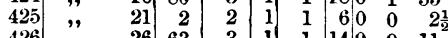

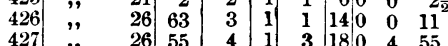

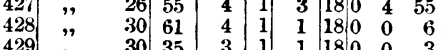

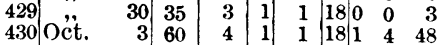

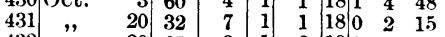

\begin{tabular}{llllllllllllll}
4332 & $\#$ & 20 & 65 & 8 & 1 & 2 & 18 & 0 & 2 & 15 \\
\hline
\end{tabular}

$\begin{array}{lllllllll}20 & 70 & 7 & 1 & 4 & 16 & 2 & 0 & 40\end{array}$

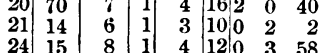

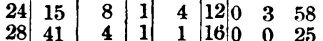

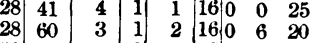

\begin{tabular}{r|rr|r|r|r|r|r|rrr|}
4388 & $\#$ & 30 & 5 & 5 & 1 & 1 & 8 & 0 & 24 \\
440 & Nö. & 31 & 70 & 2 & 1 & 1 & 18 & 0 & 0 & 9 \\
4 & 11 & 3 & 1 & 3 & 10 & 0 & 4 & 8 \\
\hline
\end{tabular}

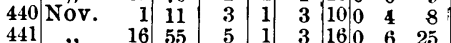

$\begin{array}{lllllllllll}16 & 55 & 5 & 1 & 3 & 16 & 0 & 6 & 25 \\ 2 & 5 & 7 & 1 & 3 & 10 & 0 & 2 & 30\end{array}$

\begin{tabular}{cccc|c|c|ccc|c}
20 & $5 \frac{1}{2}$ & 7 & 1 & 3 & 10 & 0 & 2 & 30 \\
20 & 50 & 6 & 1 & 1 & 14 & 0 & 0 & 20
\end{tabular}

\begin{tabular}{r|rr|r|r|r|rrr|}
20 & 50 & 6 & 1 & 1 & 14 & 0 & 0 & 20 \\
20 & 51 & 1 & 1 & 16 & 0 & 0 & 13
\end{tabular}

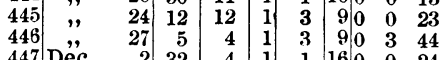

\begin{tabular}{c|c} 
uric & ," \\
\hline
\end{tabular}

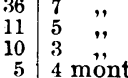

5 (12 months 5 . 72 years

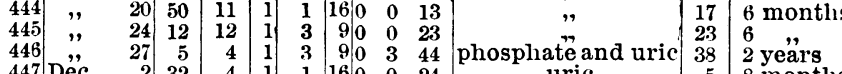

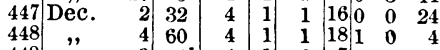

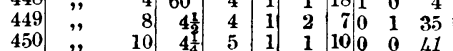

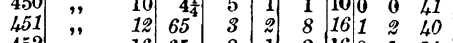

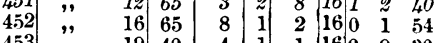

\begin{tabular}{lll|l|l|l|l|l|lll|}
453 & $\prime$ & 19 & 40 & 4 & 1 & 1 & 16 & 0 & 0 & 30 \\
\hline
\end{tabular}

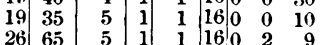

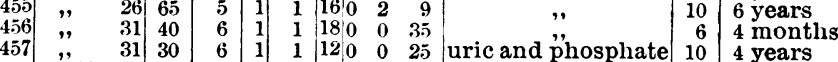

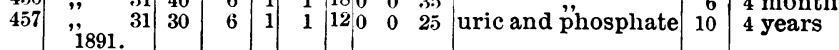

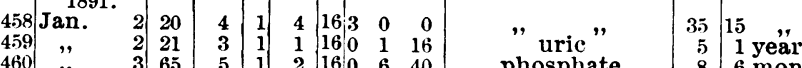

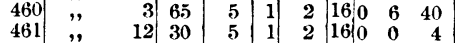

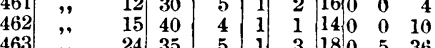

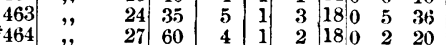

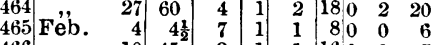

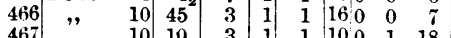

\begin{tabular}{rrr|r|r|r|rrr|rr}
467 & $"$ & 10 & 10 & 3 & 1 & 1 & 10.0 & 1 & 18 \\
468 & $"$ & 11 & 5 & 5 & 1 & 1 & 7 & 0 & 0 & 24
\end{tabular}

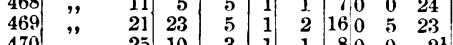

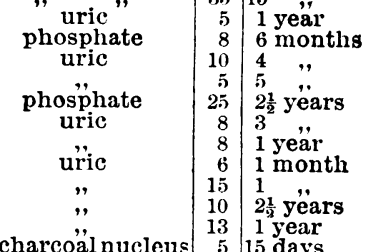


ing of December 16th. His friends would not allow a postmortem examination.

Litholapaxy in Male Children.-When, in 1885, Keegan first showed that Bigelow's operation was capable of successful extension to the case of male children, I lost no time in procuring the necessary instruments, and, applying the operation to such cases. In two papers ${ }^{2}$ I placed before the profession full details of 49 cases of litholapaxy undertaken by me in male children, or boys below the age of puberty. Since then 67 males of 15 years and under, suffering from stone, have come under treatment, and in 66 of these I have performed litholapaxy-in all, with complete success. In only one instance was it necessary to have recourse to lithotomy (suprapubic). The greater my experience of litholapaxy amongst male children becomes, the more I am fascinated by this operation. Though the average number of days such cases were kept in hospital was $5 \frac{1}{3}$ as a rule, these little patients may be seen playing about the day after the operation, perfectly happy, and untroubled by urinary symptoms of any kind. Did space permit, I could illustrate the force of this statement by details of numerous eases from my practice.

It will be observed that amongst this series there were two little patients of $2 \frac{1}{1}$, four of $2 \frac{1}{4}$, and one of 2 years respectively, from whom calculi, varying in weight from 21 to 80 grains were removed by litholapaxy, and I have previously recorded ${ }^{3}$ a case of a male child, aged $1 \frac{1}{2}$ year, from whom I removed a calculus weighing 3 grains by this operation. It is astonishing the facility with which a No. 6 cannula will pass through the urethra of a child of this age. In this connection it will not be amiss to mention that on June 7 th, 1889, a child. aged 9 months, was brought to me with symptoms of stone, but in whom no stone could be found. In this case I passed a No. 6 cannula easily, and washed out the bladder by the aspirator for diagnostic purposes. Had there been a stone I could have removed it by litholapaxy readily. Thus it will be seen that with the suitable instruments now available, litholapaxy ('an be successfully employed in patients of the most tender age.

Cases in which Cystotomy or Lithotomy was Performed.Amongst this series of $168^{\circ}$ calculous cases there were only 3 instances in which I was unable to perform litholapaxy; and, strange to say, they were all three of the same nature-calculi of medium size, lying partly in the bladder and partly impacted or sacculated in the prostatic urethra, from which position they could not be by any means displaced.

In the first of these cases, a lad of 10 years, suffering from stone for five years, I performed suprapubic cystotomy, under the impression that the stone was a large one-an impression in which examination by the rectum falsely confirmed me. The operation was performed on July 25th, 1889 , the calculus weighing 3 drachms. The patient then passed into the hands of Surgeon-Major I. Boulger on August 3rd, and was discharged cured on August 14th.

In the second case, that of a man aged 45 years, suffering for four years, median lithotomy was performed on December 17th, 1889, and the patient discharged cured on January 13th, 1890.

The third case, aged 19, was a patient on whom I had previously performed suprapubic cystotomy on June 23rd, 1887 . He remained free from urinary troubles for two years, when symptoms of stone again set in, and he applied for relief on January 24th, 1891. On passing a sound, I detected a stone at the neck of the bladder, and endeavoured to dislodge it backwards, but without effect: so I performed median lithotomy, Surgeon-Major P. de H. I Haig and Surgeon S. F. Freyer being present. I found the stone, which weighed 136 grains, lying in a cul-de-scrc at the neck of the bladder, formed in the largest part by the distended and distorted prostatic urethra, and communicating with the bladder by an opening, through which, after removal of the stone, I could pass my forefinger. The patient was discharged cured on February 15th, 1891. This man had had left lateral lithotomy performed on him when a child.

Such, then, are my most recent experiences in the surgery of

British Medical Journal, December 24th, 1887, and October 12th, 1889. 3 British Medical Journat, October 12 th, 1889 , p. 812.

4 British Medical Journal, December 24th, 1887, p. 1375. stone in the bladder. There are two very important lessons: to be learnt therefrom :-

(1) That litholapaxy is almost universally applicable to all cases of vesical calculus, as is clearly shown by the fact that I have been enabled to perform this operation in 165 out of my latest 168 cases of stone, occurring in both sexes and in all ages and conditions. During 1890, 106 patients sufferingfrom stone came under my treatment, and litholapaxy was. performed in one and all of these, with one death.

(2) That the dangers which we anticipated from the extension of litholapaxy to the case of male children were purely imaginary and had no foundation in fact, as is fully proved by my having now performed this operation in 115 males below the age of puberty without a death, and in all with complete success.

General Statistics.--In my work on Litholapaxy, "published in 1886 , I gave the results of 321 operations for stone in the bladder-128 litholapaxies and 193 lithotomies--performed by me down to the beginning of that year, with 14 deaths, and showed that the introduction of litholapaxy into my practice had had the effect of reducing the mortality from operations for stone in the adult from 18 to 5 per cent. Since that time I have in three papers published in the BrItish Menrcal. JourNaL, including the present paper, given full details of a further series of 400 cases of stone in the bladder. There were amongst these 342 litholapaxies-in 221 adult males, 5 adult females, 115 male children, and 1 female child-with 4 deaths; 54 perineal lithotomies-amongst 3 adult males and 51 male children-with 1 death ; and 4 suprapubic lithotomies: -in 2 adult males and 2 male children-with 1 death. That is to say, 400 operations with 6 deaths, or a mortality of $1 \frac{1}{2}$ per cent.- a result which we can scarcely expect to improve on whilst we extend the operation to almost hopeless and moribund patients. It is a result unequalled in any other large and important operation in surgery, and entirely due to the introduction of Bigelow's method. The grave has now closed over that great surgeon, whose name is imperishably connected with the modern operation for stone and the word "litholapaxy" which he introduced to denote and distinguish it.

\section{REMARKS ON SUPRAPUBIC AND LATERAL LITHOTOMY AND ON LITHOLAPAXY.}

By Surgeon J. A. CUNNINGHAM, M.D., I.M.S., Civil Surgeon, Mooltán, Punjab.

SLPRAPUBIC lithotomy, or "Petersen's operation," is a very admirable proceeding in suitable cases, and a great advance on the old method, in which the peritoneum was frequently wounded; but for moderately-sized stones-up to, say, $4 \frac{1}{2}$ ounces-that might be safely removed by lateral lithotomy, it is not to be compared to the latter operation, either as to. facility or simplicity of performance, safety, comfort in aftertreatment, or in the completeness of the cure-or, in other words, absence of bad effects from the operation itself. To compare it at all to litholapaxy in cases suitable for the latter is absurd.

Litholapaxy is infinitely safer than any variety of lithotomy for suitable cases -about 90 per cent. of all cases-and the patient is laid up for about four days, instead of three weeks. after the operation.

Suprapubic lithotomy is the proper operation for removing a stone that cannot be crushed with a lithotrite, and which is too large to be safely removed through a perineal wound. I think the safe limit of size to exclude from litholapaxy would be over $6 \frac{1}{2}$ ounces, although I have successfully crushed a stone at one sitting over 8 ounces, and there are published cases of larger stones having been successfully crushed. The percentage of stones met with in civilised countries over 6 ounces will always be very small. Almost all the cases of suprapubic lithotomy recently published could have been successfully dealt with by either litholapaxy or lateral lithotomy.

Suprapubic lithotomy requires more complicated arrangements - as water or air bag to dilate the rectum; it involves a a deep and sometimes, in a fat patient, a difficult dissection 6. The Modern Treatment of Stone by Litholapaxy. London: J. \& A. Churchill 